\title{
Equatorial quasiperiodic echoes from field-aligned irregularities observed over Jicamarca
}

\author{
Ronald F. Woodman and Jorge L. Chau ${ }^{1}$ \\ Radio Observatorio de Jicamarca, Instituto Geofísico del Perú, Lima
}

\begin{abstract}
This is a report of so far undescribed equatorial quasiperiodic (EQP) echoes from field-aligned irregularities from the $E$ and lower $F$ region. These echoes were observed on October 20, 1993 at the Jicamarca Radio Observatory in conjunction with a spectacular spread $F$ event. We have identified two regions where striated EQP echoes are clearly observed. The time periods are between 1 and $5 \mathrm{~min}$. In the first region $(120-140 \mathrm{~km})$ the slope of the striations is negative (apparent downward propagation), while in the second $(160-200 \mathrm{~km})$ the slope is positive. Moreover, in the first region the time periods (striation spacings) are smaller and the altitude rates of change are higher than those observed in the second region. Although these equatorial echoes appear somewhat similar to those seen at midlatitudes, we believe that the two phenomena are different. We have no explanation as yet for these EQP observations; our purpose in presenting these data is primarily to describe their properties in more detail than has been done in the past.
\end{abstract}

\section{Introduction}

In this letter we present the observations of field-aligned quasiperiodic echoes in the equatorial electrojet (EEJ) region. This type of echo has been observed in the past, as early as 1979 , in many range-time intensity maps of spread $F$ plume events but never described in detail. We present their spectral, range, and time characteristics based on data taken at the Jicamarca Radio Observatory (JRO) (1.35 dip angle at $100 \mathrm{~km}$ altitude) on October 20, 1993, during a strong spread $F$ event.

These equatorial echoes have some characteristics that are superficially similar to the so-called midlatitude quasiperiodic (QP) echoes first observed with the MU radar in Japan [Yamamoto et al., 1991]. Midlatitude QP echoes have been studied intensively with radars and in situ measurements [Fukao et al., 1998; Larsen, 2000a]. Similar QP echoes have recently been observed at low latitudes, but outside the EEJ region [Choudhary and Mahajan, 1999; Chau and Woodman, 1999]. A summary of the characteristics of most QP radar observations has been given by Chau and Woodman [1999].

Existing theories have explained the existence of QP echoes in terms of atmospheric gravity waves (AGW) modulating the sporadic $E(E s)$ layers in such a way as to make them nonlocally unstable to gradient drift processes [Woodman et al., 1991; Tsunoda et al., 1994]. However, from \footnotetext{
Perú

${ }^{1}$ Also at Laboratorio de Física, Universidad de Piura, Piura,
} Copyright 2001 by the American Geophysical Union.

Paper number 2000GL000076.

0094-8276/01/2000GL000076\$05.00 recent results obtained at different sites (e.g., positive slopes of the striations, very short time periods) these theories need to be revisited. Recently, Larsen [2000b] has suggested a possible role of shear instabilities and the associated KelvinHelmholtz structure in seeding the plasma instabilities that produce the radar echoes.

Given the wide range of latitudes where QP echoes have been observed, an obvious question is whether or not such echoes are observed over the equator. What we see at $\mathrm{Ji}$ camarca seems to be substantially different from the midlatitude echoes, as we shall see, and so we have labeled the Jicamarca echoes as EQP (for Equatorial QuasiPeriodic), reserving QP for those phenomena that were observed first with the MU radar.

\section{Quasiperiodic Observations at Jicamarca}

In Figure 1 we present an altitude-time distribution of signal-to-noise ratio (SNR) of a spectacular spread $F$ event that was recorded at the Jicamarca Radio Observatory on October 20, 1993 in a vertical-drift observational mode. An approximate horizontal scale, parallel to the time axis, has been added to the figure by assuming that the zonal plasma drift is eastward with a constant value of $110 \mathrm{~m} \mathrm{~s}^{-1}$ and that

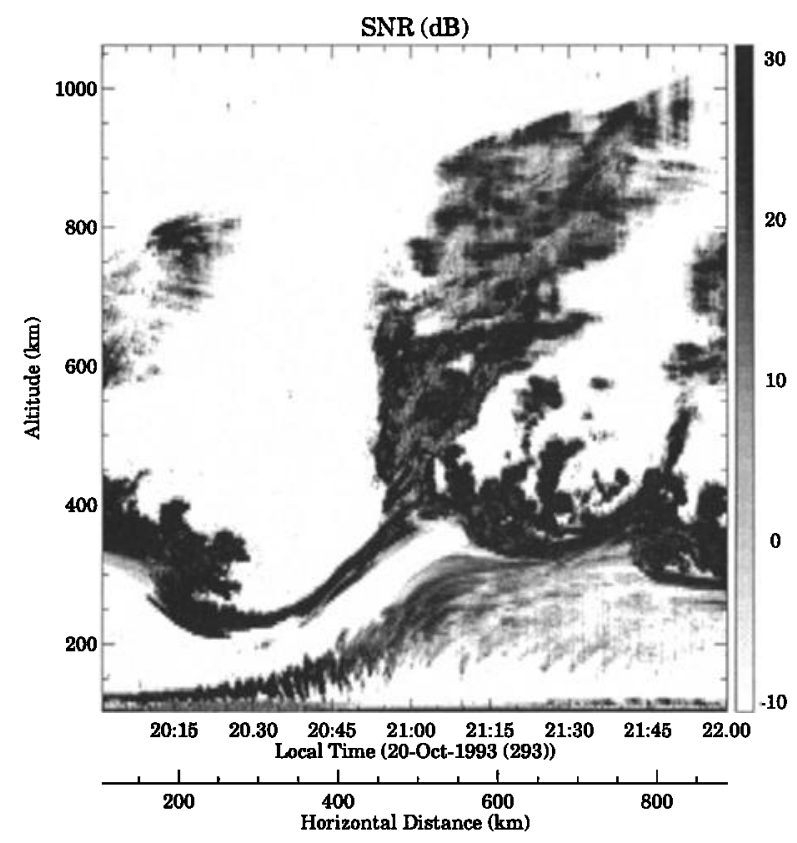

Figure 1. Altitude-time distribution of signal-to-noise ratios during a spread $F$ event. An approximate horizontal scale has been added to the time axis, assuming a constant drift speed of $110 \mathrm{~m} \mathrm{~s}^{-1}$. Note the well-defined quasiperiodic striations below $200 \mathrm{~km}$. 
the structure is frozen in this frame of reference. Characteristics of similar types of spread $F$ events have been reported and discussed extensively in the literature [Woodman and La Hoz, 1976; Kelley et al., 1981; Hysell et al., 1990] and we will not discuss them further.

In this paper we concentrate on the EQP echoes observed below $200 \mathrm{~km}$. Similar EQP echoes have been observed, but not described in detail, in previous spread $F$ events (e.g., Hysell et al. [1990], Figure 1, after 2130 LT; and Kelley et al. [1981], Figure 3) and they have been associated with the so-called valley-type echoes [Woodman and $\mathrm{La} \mathrm{Hoz,} \mathrm{1976]}$ because of the region of occurrence.

In Figure 1, EQP striations with negative slopes are observed before $2100 \mathrm{LT}$ and below $200 \mathrm{~km}$, while EQP striations with positive slopes are observed after $2110 \mathrm{LT}$ and are centered around $185 \mathrm{~km}$. The latter striations show an apparent altitude rate of change of $\sim 80 \mathrm{~m} \mathrm{~s}^{-1}$, are weaker, and are characterized by longer time periods ( $\sim 4 \mathrm{~min})$ and larger vertical striation spacings $(\sim 40-50 \mathrm{~km})$ than the former. Moreover, the mean Doppler velocities (positive towards the radar) of the latter echoes are negative ( $\sim-10$ to $-20 \mathrm{~m} \mathrm{~s}^{-1}$ ), and the spectral widths are between 50 and
$100 \mathrm{~m} \mathrm{~s}^{-1}$, results that are not shown here. The altitude rate of change of the striations is only an apparent rate because under the vertical drift observational mode used, it is difficult to determine if the striations are due to frozen structures drifting horizontally or to blobs moving inside the beam.

In order to better describe the lower EQP striations (i.e., before 2100 LT), in Figure 2 we show the SNR, Doppler velocity and spectral widths of such striations. From Figure $2 \mathrm{a}$, we see that these striations have a period of $\sim 1.5 \mathrm{~min}$ and a spacing of $\sim 20 \mathrm{~km}$. The altitude of the center of these striations increases with increasing time at a rate of $\sim 47 \mathrm{~m} \mathrm{~s}^{-1}$ starting at $120 \mathrm{~km}$. This velocity is similar to the velocity of the irregularities in the bottom $F$ layer, which in turn is statistically comparable to the background vertical drift velocity. The slope of the striations is negative, with an apparent altitude rate of change of $\sim-417 \mathrm{~m} \mathrm{~s}^{-1}$. Note that these lower striations occurred when $E$ region irregularities were drawn into an $F$ region plume. The physical picture we have in mind for this process is that the polarization charges produce a localized electric field responsible for the fast updraft drift of the low density plasma at the neck

(a) SNR (dB)

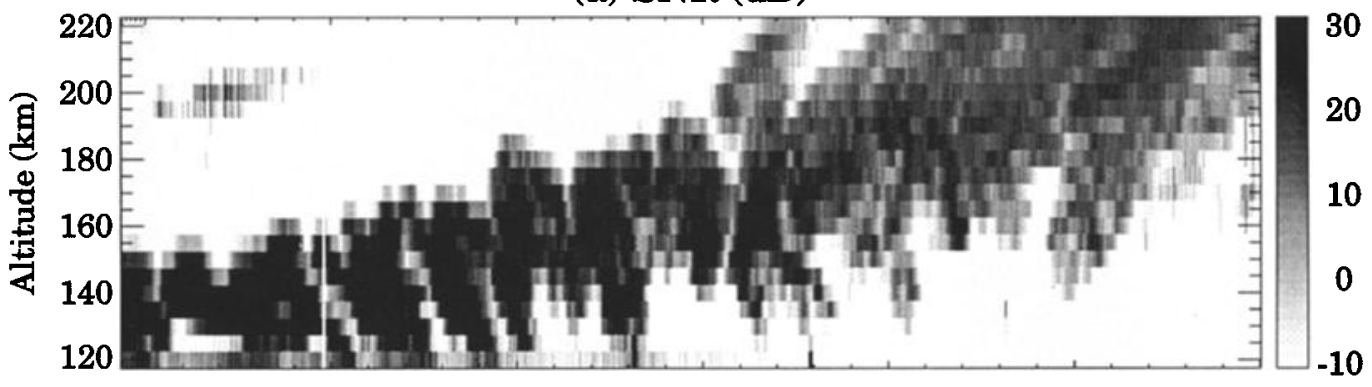

(b) Doppler Velocity (m s')

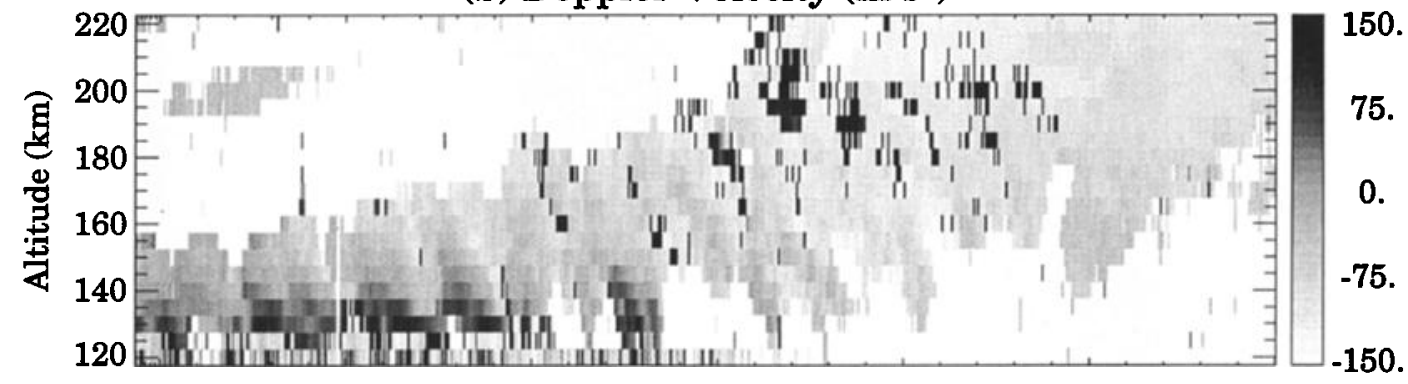

(c) Spectral Width (m s $\left.{ }^{-1}\right)$

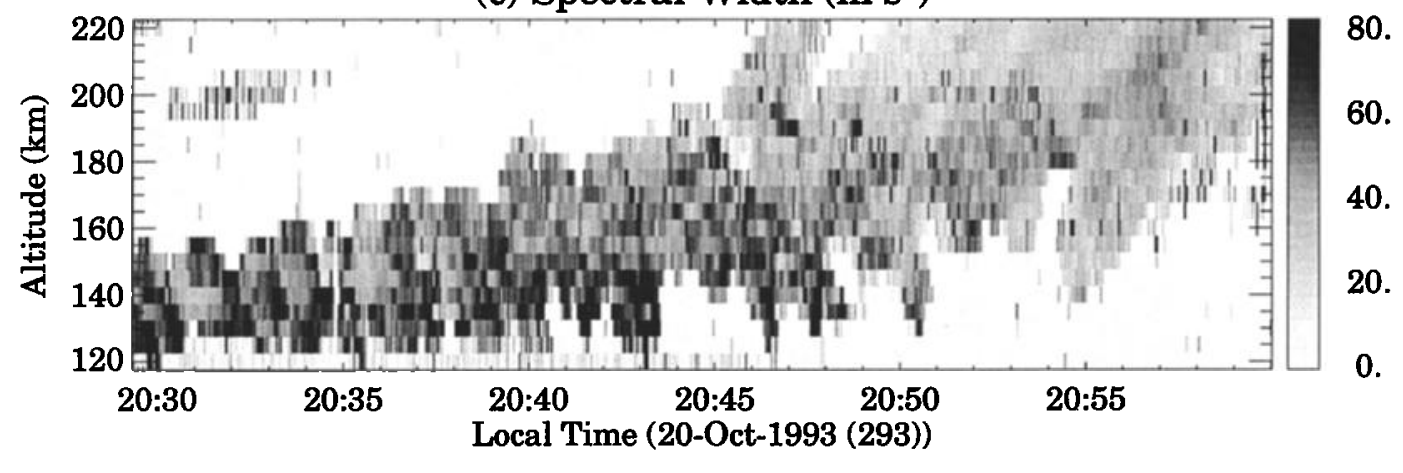

Figure 2. Altitude-time distributions of a) SNR, b) Doppler velocity, and c) Spectral width, from 2030 LT to 2100 LT, when quasiperiodic echoes are clearly observed in the equatorial $E$ region. 
of the plumes. These same charges produce an electric field in the valley region which causes the uplift of the low density plasma encountered there, including the $E$ region. This characteristic was also present in previous observations.

The region between 120 and $140 \mathrm{~km}$ corresponds to a positive mean Doppler velocity $\left(\sim 50 \mathrm{~m} \mathrm{~s}^{-1}\right)$, while above $140 \mathrm{~km}$ the mean Doppler velocity is negative (see Figure 2b). Note some aliasing problems (black spots above $140 \mathrm{~km}$ ) that are due to the Nyquist frequency used. The mean spectral widths are between 30 and $60 \mathrm{~m} \mathrm{~s}^{-1}$ (see Figure 2c).

In both regions, the velocity direction of the irregularities coincides with the slope of the striations, e.g., when the irregularities move away from the radar, the striations have positive slopes (i.e., also away). However, the magnitudes of the Doppler velocities of the irregularities are smaller than the apparent rate of change of altitude of the striations.

\section{Concluding Remarks}

Although our observations are based only on few hours of data, they are a fairly common event that occurs over Jicamarca, at least when strong spread $F$ events occur and $E$ region echoes are drawn into the $F$ region. The observations presented are one more manifestation of $E$ and lower $F$ region equatorial irregularities which need a physical explanation.

Some characteristics of these EQP echoes are similar to those of QP echoes observed at midlatitudes. For example, they are observed as periodic striations, come presumably from field-aligned ionospheric irregularities, and show similar time periods. However, midlatitude QP striations have not been observed above $130 \mathrm{~km}$ altitude and they are not related to the occurrence of spread $F$.

Given the different slopes observed, the large spacings, and the height of occurrence of these echoes, the existence of EQP cannot be explained by any of the existing theories that have been postulated to explain the QP echoes.

Acknowledgments. We would like to thank D. T. Farley for helping us improve the original manuscript. The Jicamarca Radio Observatory is operated by the Geophysical Institute of Perú, with support from the NSF Cooperative Agreement ATM9408441. J. L. C. was supported by the National Science Foundation under agreement ATM-9813910.

\section{References}

Chau, J. L., and R. F. Woodman, Low-latitude quasiperiodic echoes observed with the Piura VHF radar in the $E$ region, Geophys. Res. Lett., 26, 2167-2170, 1999.

Choudhary, R. K., and K. K. Mahajan, Tropical $E$ region field aligned irregularities: Simulatneous observations of continuous and quasiperiodic echoes, J. Geophys. Res., 104, 2613-2619, 1999.

Fukao, S., M. Yamamoto, R. T. Tsunoda, H. Hayakawa, and T. Mukai, The SEEK (Sporadic- $E$ experiment over Kyushu) campaign, Geophys. Res. Lett., 25, 1761-1764, 1998.

Hysell, D. L., and J. D. Burcham, HF radar observations of quasiperiodic $E$ layer echoes over North America, J. Geophys. Res., 104, 4361-4371, 1999.

Hysell, D. L., M. C. Kelley, W. E. Swartz, and R. F. Woodman, Seeding and layering of equatorial spread $F$ by gravity waves, J. Geophys. Res., 95, 17,253-17,260, 1990.

Kelley, M. C., M. F. Larsen, C. La Hoz, and J. P. McClure, Gravity wave initiation of equatorial spread $F$ : A case study, J. Geophys. Res., 86, 9087-9100, 1981.

Larsen, M. F., Coqui 2: Mesospheric and lower thermospheric wind observations over Puerto Rico, Geophys. Res. Lett., 27, $445-448,2000$ a.

Larsen, M. F., A shear instability seeding mechanism for quasiperiodic radar echoes, J. Geophys. Res., in press, $2000 \mathrm{~b}$.

Tsunoda, R. T., S. Fukao, and M. Yamamoto, On the origin of quasi-periodic radar backscatter from midlatitude sporadic $E$, Radio Sci., 29, 349-365, 1994.

Woodman, R. F., and C. La Hoz, Radar observations of $F$ region equatorial irregularities, J. Geophys. Res., 81, 5447-5466, 1976.

Woodman, R. F., M. Yamamoto, and S. Fukao, Gravity wave modulation of gradient drift instabilities in midlatitude sporadic $E$ irregularities, Geophys. Res. Lett., 18, 1197-1200, 1991.

Yamamoto, M., S. Fukao, R. F. Woodman, T. Ogawa, T. Tsuda, and S. Kato, Midlatitude $E$ region field-aligned irregularities observed with the MU radar, J. Geophys. Res., 96, 15,943$15,949,1991$.

J. L. Chau and R. F. Woodman, Radio Observatorio de Jicamarca, Apartado 13-0207, Lima, Perú (e-mail: chau@geo.igp.gob.pe; ron@geo.igp.gob.pe)

(Received April 4, 2000; revised September 28, 2000; accepted October 13, 2000.) 